INFORMATION ACTIVISM 
SIGN,

STORAGE,

TRANSMISSION

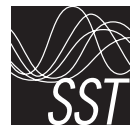

A series edited by Jonathan Sterne and Lisa Gitelman 


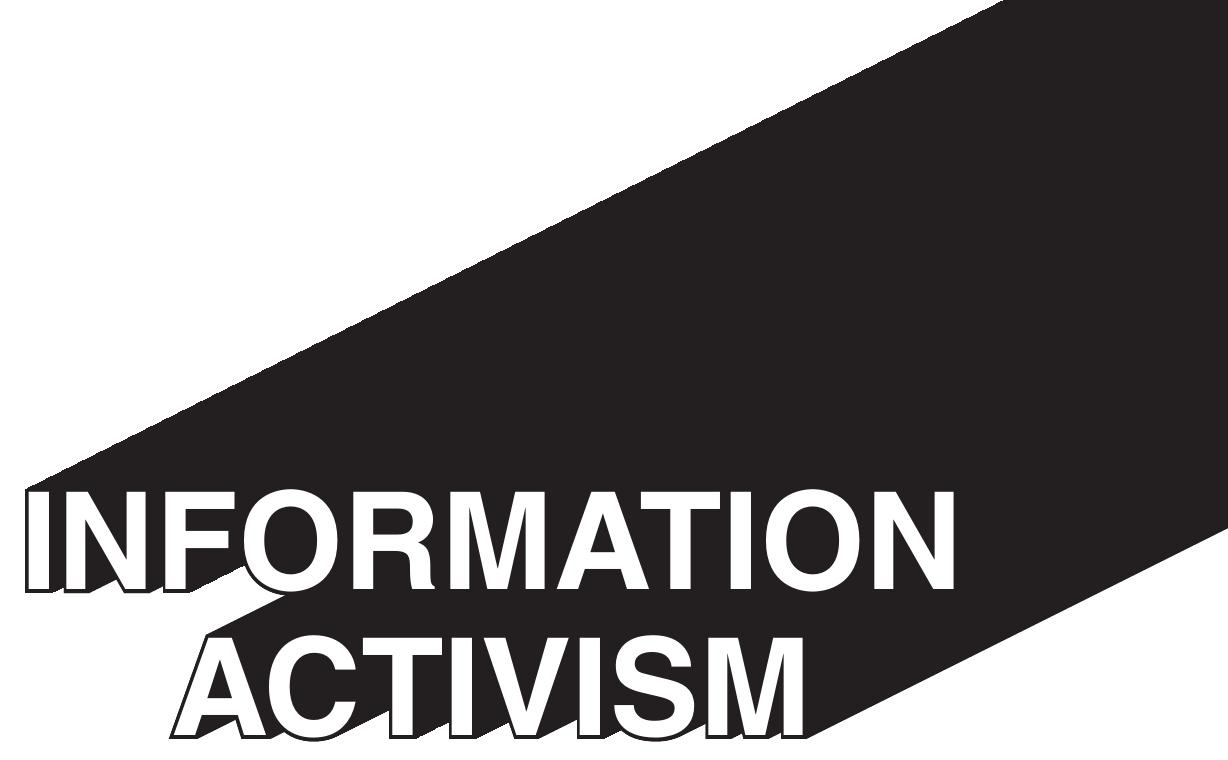

\author{
A Queer History \\ of Lesbian Media
}

Technologies

\title{
CAIT MCKINNEY
}


(C) 2020 Duke University Press

All rights reserved

Printed in the United States of America on acid-free paper $\infty$ Designed by Aimee C. Harrison

Typeset in Minion Pro, Helvetica LT Std, and IBM Plex Mono by Westchester Publishing Services

Library of Congress Cataloging-in-Publication Data

Names: McKinney, Cait, [date] author.

Title: Information activism : a queer history of lesbian media technologies / Cait McKinney.

Other titles: Sign, storage, transmission.

Description: Durham : Duke University Press, 2020. I Series: Sign, storage, transmission I Includes bibliographical references and index.

Identifiers: LCCN 2019046772 (print) I LCCN 2019046773 (ebook) ISBN 9781478007821 (hardcover)

ISBN 9781478008286 (paperback)

ISBN 9781478009337 (ebook)

Subjects: LCSH: Lesbian Herstory Archives. I Lesbians-Archival resources. I Lesbian feminism-Archival resources. I Digital media-Social aspects. I Archives-Social aspects. I Archival materials-Digitization-Social aspects. I Queer theory.

Classification: LCC HQ75.5 .M44 2020 (print) I LCC HQ75.5 (ebook) | DDC 306.76/63-dc23

LC record available at https://lccn.loc.gov/2019046772

LC ebook record available at https://lccn.loc.gov/2019046773

Cover art: Based on the cover of a call log created by the Lesbian Switchboard of New York City, 1980-81. Lesbian Switchboard Records, box 2, folder 35, The LGBT Community Center National History Archive. 
for Hazel 
This page intentionally left blank 